\title{
O conhecimento do conteúdo relevo: contribuições metodológicas
}

\begin{abstract}
Resumo: De modo geral, avalia-se que discussões metodológicas em trabalhos no campo da Geografia são ainda tímidas. Não raras vezes, os artigos e relatórios geográficos, qualitativos e quantitativos, apresentam a metodologia de forma parcial, sem explicitar bases teóricas, dilemas, dúvidas e o identificar de possibilidades que levaram a que se optasse por esse ou aquele caminho. Considera-se que tal abordagem possa restringir a compreensão dos registros de uma pesquisa e o reconhecimento/ validação científica por pares em outros campos. Este trabalho objetiva apresentar ações dedicadas à investigação dos conhecimentos da matéria relevo, mobilizadas por professores de Geografia para construção de práticas pedagógicas na Educação Básica. Espera-se contribuir à compreensão da metodologia como decorrente do diálogo entre esses aspectos e as questões que se busca responder em uma investigação.
\end{abstract}

\section{Knowledge of relief content: methodological contributions}

\begin{abstract}
On a general way, we appraise that methodological discussions in Geography works are yet very shy. Not rarely, papers and reports, both qualitative or quantitative, show their methodology in a partial manner, without explaining theoretical basis, dilemmas, doubts and the identification of possibilities which drove to this or that way. We consider that such approach may limit the understanding of a research records and the acknowledgement/scientific validation from pairs in other fields. With these points in mind, this work was formulated, with the objective of showing actions dedicated to the investigation of knowledge inside the relief subject, mobilized by Geography teachers for building of pedagogical practices on basic education. Such effort, we hope, may contribute to the understanding of the methodology as a consequence of dialogue between these aspects and the questions we try to answer in a investigation.
\end{abstract} Valeria de oliveira roque
Ascenção*

*Professora Adjunta Departamento de Geografia Instituto de Geociência da Universidade Federal de Minas Gerais

Palavras-chave: Metodologia; Conhecimento docente; Conhecimento do conteúdo.

Key-Words: Methodology, Teaching Knowledge, Knowledge of content 


\section{Introdução}

O contato com trabalhos em diferentes áreas do campo geográfico levou a afirmar que 0 delineamento da metodologia que embasa uma dada investigação, em geral, aparece timidamente nos textos de divulgação. Mais que isso, esse contato permite afirmar que que os investimentos metodológicos ficam restritos, em inúmeros casos, ao elencar de procedimentos e, consequentemente, a uma concepção reduzida de metodologia.

Compreende-se a metodologia como o eixo vertebral de uma pesquisa cujas reflexões envolvem a definição do objeto que se investiga, a construção da problemática, possíveis redefinições das bases teóricas, objetivos, instrumentos, enfim, todas as ações básicas de uma pesquisa. Assim compreendida, questiona-se o fato de que relatórios de pesquisa, especificamente para fins deste trabalho, dissertações e teses no campo da Geografia, restrinjam-na à descrição de procedimentos e técnicas. Essa perspectiva favorece uma simplificação na compreensão da finalidade e função da metodologia.

Fosse o problema somente a ausência das discussões metodológicas nos relatórios e artigos divulgadores de pesquisas em Geografia, seria menor. Contudo, como se levantou anteriormente, em geral inúmeras dissertações e teses reduzem a metodologia a um trecho reduzido, na maioria das vezes, estanque ao restante da discussão; descrevem-se os instrumentos sem que se indique o por que deles se lançou mão, sem que se explicite que modo esses favorecerão a interpretação do objeto e da questão que se investiga. Nessa perspectiva, avalia-se que as ações de pesquisa sejam naturalizadas e não decorrente de escolhas, pois as mesmas não são justificadas através da teoria, do objeto pesquisado, da questão de pesquisa e dos objetivos pretendidos.

Pérez \& outros (2001), ao discorrerem sobre os encaminhamentos do ensino de Ciências na educação básica e das pesquisas voltadas para tal temática, afirmaram que a ausência de uma metodologia bem estruturada por pode provocar "deformações" no "conhecimento" produzido.

Por tudo isso, decidiu-se produzir um trabalho dedicado a apresentar algumas das reflexões metodológicas que respaldaram uma investigação acerca dos conhecimentos da matéria relevo junto aos professores de Geografia. Ao se expor as referidas reflexões pretende-se evidenciar a trama que constituiu um trabalho de pesquisa. A noção de metodologia que moveu a "pesquisa exemplo" buscou incorporar as críticas aqui expostas. e ações que levaram a definição do objeto, elaboração da pergunta, estabelecimento da hipótese, das bases teóricas, das ações e instrumentos de investigação. É sob tal perspectiva, que se compreende a metodologia como o eixo que estrutura os trabalhos de pesquisa.

Neste artigo se apresentará alguns caminhos metodológicos assumidos pela "pesquisa exemplo". Tal pesquisa teve um caráter exploratório, cujo objetivo foi identificar e interpretar os conhecimentos do conteúdo relevo mobilizados por professores de Geografia, atuantes no segundo segmento do ensino fundamental.

Por fim, avalia-se necessário apresentar dois esclarecimentos. 0 primeiro refere-se a base para a produção das críticas às orientações metodológicas dos trabalhos em Geografia. Para além da imersão na literatura do campo a produção deste artigo demandou um exame, ainda que breve, de dissertações e teses defendidas em quatro programas de pós-graduação em Geografia. Elegeu-se para tanto os programas com maior produção, segundo os referencias da Capes (2011). Foram examinados dezesseis trabalho defendidos no ano de 2011, escolhidos através de sorteio, alocados tanto na subárea da "Geografia Humana", como na subárea da "Geografia Física". Do total analisado, somente

Geografia Ensino \& Pesquisa, v. 17, n.1 p. 119-132, jan./abr. 2013

O conhecimento do conteúdo relevo: contribuições metodológicas três deixaram transparecer a metodologia decorrente da interação entre elementos constituintes da pesquisa. Nesses, não se tem um capítulo metodológico, mas sim uma metodologia que se imiscui no texto sustentando a investigação. Tais trabalhos se associam a subárea Humana da Geografia.

Esclarece-se ainda que, embora não seja objetivo deste trabalho trazer uma análise minuciosa dos textos analisados, a leitura dos mesmos permitiu a identificação de limites quanto a compreensão da metodologia nos trabalho das subáreas Física e Humana. Na primeira sobressai 
a redução da metodologia aos instrumentos utilizados. Na outra, a apresentação teórica, não raramente, não explicita os vínculos com os procedimentos, mais precisamente, a teoria ganha vida própria nos trabalhos que acabam por tornar-se um "pretenso libelo" teórico. Optou-se por omitir o nome das instituições e dos trabalhos analisados, pois não se buscou uma exposição dos pares, mas sim o levantamento de um questionamento que, pensa-se, é premente.

Para fins deste artigo se focará nas decisões que levaram à seleção dos sujeitos de investigação e a aproximação dos conhecimentos do conteúdo "relevo" mobilizado por esses sujeitos.

\section{Alguns Caminhos...}

Os referenciais teóricos que subsidiaram a pesquisa cuja metodologia será aqui parcialmente apresentada, embasaram os encaminhamentos metodológicos e foram basilares para a identificação qualitativa dos conhecimentos dos docentes geógrafos frente ao conteúdo relevo e do modus de operação conceituais dos sujeitos de investigação do trabalho - professores de Geografia atuantes nos anos finais do Ensino Fundamental. Tais caminhos foram desenhados a partir da articulação entre referenciais teórico-metodológicos próprios do campo da Geografia, anuentes aos conhecimentos docentes segundo as proposições de Shulman (1986), instrumentos do Repertório Grid (FERNANDES, 2009) e da Análise de Conteúdo (1977).

A referida pesquisa teve por princípio que professor é um componente fundamental aos processos de desenvolvimento educacional. Nessa perspectiva, torna-se fundamental a realização de investigações que tomem o conhecimento do geógrafo docente como objeto, ressaltando-se, aquelas atinentes ao conhecimento do conteúdo por esse profissional (IDEM, 1986). Trabalhos nessa direção podem apresentar importantes contribuições para o estabelecimento de políticas e propostas para formação docente e, consequentemente, para a estruturação de uma educação democrática e de qualidade.

Contudo, ressalta-se que a identificação dos conhecimentos da matéria mobilizados pelos professores deve tomar cuidados para não recair em impressões valorativas, que acabam ganhando tom classificatório - o professor que sabe mais e o professor que sabe menos. Como destaca Shulman (1986), trabalhos com fim valorativo pouco contribuem para a compreensão das engrenagens que se movimentam quando da mobilização de um conhecimento. Acredita-se que a compreensão de tais engrenagens possa favorecer a formação (inicial e continuada) de professores.

$\mathrm{O}$ conhecimento do professor faz a diferença? Essa pergunta deu origem aos trabalhos sobre o conhecimento pedagógico do conteúdo (PCK), desenvolvidos por Shulman a partir de 1986. Tais trabalhos, para além de darem centralidade ao conhecimento do professor, desenharam uma estrutura epistêmica para esse. Diz-se isso considerando que, Shulman e outros que o seguiram, indicaram as diferentes esferas que constituem esse conhecimento, entre as quais, o conhecimento da matéria ou conteúdo. Essa face do conhecimento docente, associada a conhecimentos do campo da Educação, compõe o conhecimento pedagógico do conteúdo (PCK), matéria-prima para a estruturação das práticas pedagógicas (SHULMAN, 1986).

Para Grossman, Wilson e Shulman (2005), o reconhecimento do PCK pode favorecer ao professor: i- a identificação e seleção de informações objetivas a serem trabalhadas junto aos alunos; ii- a organização de princípios e conceitos centrais de uma matéria e que serão trabalhados nas práticas docentes.

Desse modo, ao se desenvolver estratégias metodológicas pretendeu-se favorecer a vista das muitas facetas da questão geral da pesquisa, cujo foco central se refere a uma das faces do conhecimento da matéria - ou do conteúdo.

Com base em García Canclini (2003), se construiu um caminho investigativo marcado pela hibridização de teorias e procedimentos metodológicos, que considera a associação entre o diverso passível de superar hierarquias, realocar ideias e conceitos, de modo a atender o fenômeno que se pretende interpretar. A combinação de ações metodológicas distintas pareceu a saída para a

Geografia Ensino \& Pesquisa, v. 17, n.1 p. 119-132, jan./abr. 2013

\section{Ascenção V. O. R.}


interpretação de diferentes fontes pedagógicas que, em interação, contribuem para a constituição dos conhecimentos mobilizados pelo professor quando do ensino de um conteúdo.

A análise dos dados teve por base as ideias de Shulman (1986) e Grossman \& outros (2005). Os instrumentos empregados pela Análise de Conteúdo (BARDIN, 1971) e do Repertório Grid (FERNANDES, 2009) não aparecem, na pesquisa exemplo, em sua forma pura e foram utilizados tanto para a obtenção, como para a leitura dos dados obtidos.

A interpretação dos dados de pesquisa se fez a partir da triangulação desses com os referenciais teóricos específicos aos campos da Geomorfologia, da Educação e da área do ensino de Geografia. A análise de cada fonte considerou ainda que múltiplas interações podem ocorrer dentre as mesmas, exigindo assim o diálogo entre todas.

\section{Nossos sujeitos/pares da pesquisa}

A revisão da bibliografia brasileira sobre o conhecimento docente, concernente aos últimos 10 anos, indicou que a média de trabalhos referentes ao estudo do conhecimento docente correspondeu, aproximadamente, a $13 \%$ do total de trabalhos presentes nos anais da Associação Nacional de Pós-Graduação e Pesquisa em Educação (Anped).

Ao refinar-se o levantamento concentrando-se na identificação de discussões específicas à investigação dos conhecimentos mobilizados pelos professores quando da abordagem de um conteúdo em um dado campo do conhecimento, o percentual de trabalhos reduziu-se para $2 \%$ (média) do total de pesquisas apresentadas. Destaca-se ainda que, essas publicações referem-se, principalmente, à área do ensino de Matemática.

No que tange ao Ensino de Geografia, ainda que seja essencial afirmar o aumento de pesquisas dedicadas a essa área, constatou-se, nos anais do Encontro Nacional de Prática de Ensino de Geografia (ENPEG 2009 e 2011), que o número de trabalhos referentes aos conhecimentos portados pelos geógrafos docentes é ainda pouco expressivo. Condição similar é registrada quando se investigam os títulos disponíveis no Banco de Teses da Capes, entre os anos de 2000 a 2010, onde $o$ índice de trabalhos que abordam ou tangenciam a questão do conhecimento do docente é inferior ao número de textos dedicados a discussões mais genéricas sobre o Ensino de Geografia, correspondendo a $0,75 \%$ do total.

Esse panorama aponta para uma lacuna nos estudos sobre o Ensino de Geografia, pois pouco se investiga sobre a relação dos docentes geógrafos com o ensino de um conteúdo ou um conceito.

A constatação do quadro anterior foi fundamental para a definição do objeto da pesquisa desenvolvida durante o doutorado: o conhecimento do conteúdo relevo mobilizado por professores de Geografia.

A identificação da incipiência desses estudos foi decisiva para a demarcação da pesquisa que se realizou como uma investigação de caráter exploratório, pois se considerou o fato de que, na área do ensino de Geografia, pesquisas com esse foco são ainda incipientes, sendo necessário um mapeamento inicial que contribua para o desenvolvimento de novas concepções e questões a serem investigadas posteriormente (DUARTE, 2002).

No que diz respeito a tomada dos conhecimentos da matéria relevo mobilizado por professores de Geografia como objeto de pesquisa a incipiência é ainda maior, demandando assim um

Geografia Ensino \& Pesquisa, v. 17, n.1 p. 119-132, jan./abr. 2013

O conhecimento do conteúdo relevo: contribuições metodológicas tatear entorno da questão central, de modo a se estabelecer elementos que pudessem contribuir com o entendimento da questão de pesquisa. Tal tateamento, perene ao longo da investigação, foi decisivo para a definição das fontes, dos instrumentos e das bases interpretativas dos dados de pesquisa.

Admitiu-se ainda que uma investigação dedicada à interpretação do conhecimento docente demanda um olhar próximo sobre objeto de pesquisa. Por isso, consoante com tal percepção, adotou- 
-se o recurso das entrevistas semi-estruturadas como material empírico privilegiado e demarcou-se, como critério precípuo, que a seleção dos sujeitos entrevistados ilustrasse, mesmo parcialmente, a diversidade do perfil profissional dos mesmos. Nesse sentido, a pesquisadora definiu que a seleção dos sujeitos deveria contemplar professores que atuassem em redes de ensino distintas (pública estadual; pública municipal e rede privada) e com diferentes tempos de vivência profissional.

Como Duarte (2002), reconhece-se que os critérios para a seleção de sujeitos interferem "diretamente na qualidade das informações a partir das quais será possível construir a análise e chegar à compreensão mais ampla do problema" (IDEM, 2002:141). Portanto, ao estabelecê-los, procurou-se demarcações que referendassem a diversidade no perfil profissional dos professores, entendendo-se que essa possa provocar diferenças quanto à mobilização do conhecimento do conteúdo. Nessa direção, a seleção dos sujeitos considerou quatro aspectos relevantes para a constituição do profissional da docência (HUBERMAN, 1992): a - ter cursado graduação em Geografia; b - lecionar Geografia no segundo segmento do ensino fundamental; $c$ - afirmar trabalhar o relevo e suas dinâmicas junto aos alunos; $d$ - ter entre 02 e 10 anos de vivência profissional.

0 primeiro justifica-se no fato de que nem todos os que lecionam Geografia graduaram-se nessa área do conhecimento. No caso das escolas estaduais mineiras o processo de contratação faz com que essa disciplina escolar seja ministrada, muitas vezes, por profissionais licenciados ou graduados em outras áreas do conhecimento.

Como Shulman (2001), se aceita a existência de uma postura diferenciada frente ao conhecimento quando se observam docentes generalistas e docentes de conteúdo. Os segundos, ainda que apresentando limites no trato com o conhecimento, demonstram maior segurança para 'ousar' quando da organização de suas práticas pedagógicas. Acreditando na competência para a ousadia, optou-se pelos professores alocados no segundo grupo - docentes habilitados em Geografia.

Mas, por que pesquisar professores atuantes no segundo segmento do ensino fundamental?

De acordo com Allain et alii ( 2005), o trabalho com conceitos e conteúdos referentes às disciplinas escolares está mais claramente demarcado nessa fase de ensino do que na antecedente - ensino fundamental I. Esse enfoque se faz a revelia das indicações presentes nos Parâmetros Curriculares Nacionais (1998), que indica a escola como espaço para a socialização de conhecimentos específicos das diferentes áreas do saber. Todavia, ressalta-se que a formação de professores generalista no Brasil, não proporciona a esses elementos que os permitam trabalhar as especificidades das diferentes disciplinas escolares.

A exclusão do ensino médio como nível de pesquisa, baseou-se em depoimentos de professores das redes pública e privada de ensino (DEL GAUDIO, 2006), os quais afirmam que a finalidade precípua do ensino médio é o atendimento as demandas postas pelos concursos vestibulares ou para o ENEM (Exame Nacional do Ensino Médio). Para a autora, ainda que os documentos oficiais não corroborem com tal afirmativa é possível observar que, socialmente seja essa a expectativa dos educandos para o ensino nesta faixa educacional. Neste sentido, as finalidades do trabalho com o relevo e suas dinâmicas no ensino médio podem vir a se distanciar das posições acadêmicas e oficiais postas ao ensino de Geografia, ou seja, podem não ter como foco o favorecimento e fortalecimento da participação civil, consciente, na organização e reorganização espacial.

Para professores de Geografia, atuantes no segundo segmento do ensino fundamental, essa fase escolar identifica-se com a procura de uma prática pedagógica que favoreça aos alunos a aprendizagem de conteúdos, conceitos, habilidades, a fim de que esses produzam reflexões sobre a própria vivência e dos demais sujeitos sociais (ROQUE ASCENÇÃO, 2003). Nessa perspectiva, a aprendizagem escolar toma o conhecimento da matéria como um possível promotor de novas percepções do real, pautadas pela possibilidade de reinvenção e reorganização dos espaços, sobretudo, aqueles da escala do cotidiano. Essas noções são consoantes a proposta pedagógica contida nos PCNs $5^{\mathrm{a}}$ a $8^{\mathrm{a}}$ série (MEC, 1998), voltados para o segundo segmento do Ensino Fundamental.

Assim, considerando as demandas e expectativas postas a cada um dos níveis que compõe o ensino básico (excetuando o infantil), o segundo segmento do nível fundamental pareceu o que

Geografia Ensino \& Pesquisa, v. 17, n.1 p. 119-132, jan./abr. 2013

\section{Ascenção V. O. R.}

ISSN 2236-4994 123 
apresentava maior coerência com os objetivos do que se pretendia investigar. Por tudo isso, definiu-se que os sujeitos de pesquisa seriam professores atuantes nesse segmento educativo.

0 terceiro aspecto que fez definir os sujeitos de investigação - afirmar trabalhar o relevo e suas dinâmicas junto aos alunos - pode parecer óbvio ao ensino de Geografia, mas não o é. Existem professores que desconsideram o trabalho com os aspectos físicos constituintes do espaço geográfico (ROQUE ASCENÇÃO, 2004).

Como orientadora de Estágios Supervisionados em Licenciatura esta autora pôde perceber algumas dificuldades e preferências (opções) vivenciadas pelos docentes quando do trabalho com as dimensões físicas do espaço, especificamente, o relevo. Não raras vezes, os estagiários ouviam afirmativas docentes indicando que 'os alunos gostam mais de discussões políticas, de falar das questões da atualidade. Relevo é muito abstrato' (depoimento oral, 2004). Falas como a anterior sugeriram que 0 trabalho com a matéria relevo fosse um obstáculo, para alunos e, talvez, para professores. Conjecturou-se que os segundos podem optar pelo abandono desse conteúdo em suas práticas pedagógicas e não pela busca de caminhos que aproximem os conhecimentos sobre 0 relevo da realidade vivida pelos alunos. A reincidência de tal postura docente durante os estágios justificou assumi-la como um dos critérios de seleção dos entrevistados.

Limites diante da matéria relevo já haviam sido identificados por Roque Ascenção (2003), quando de uma pesquisa desenvolvida junto a docentes de Geografia de um município onde se implementava uma proposta de renovação pedagógica. Frente às proposições de renovação, os professores de Geografia afirmaram limites para o desenvolvimento de práticas pedagógicas que, com base no conteúdo relevo, pudessem favorecer aos educandos a interpretação de situações espaciais cotidianas. Esse foi associado às impressões construídas através dos estágios. Juntos, atuaram na constituição do objeto pesquisado e na demarcação de um critério para definição dos sujeitos de pesquisa.

Parte-se agora, para o esclarecimento do último critério que balizou a definição dos sujeitos de pesquisa: o tempo de exercício profissional. Este aspecto fundamenta-se em Huberman (1992), quando este discute os ciclos de desenvolvimento profissional. Mesmo reconhecendo o risco de naturalização do desenvolvimento profissional quando se toma por referência a categorização proposta por Huberman (ANJOS, 2008), optou-se por utilizá-lo. Argumenta-se tal categorização como um olhar sobre a carreira docente, desde que articulada a outras dimensões dessa profissão. Nesta articulação é relevante que se associe as ideias de Huberman aos aspectos históricos, sociais e culturais que, para além do tempo profissional, compõe o professor. Acredita-se que este exercício contribua para o entendimento das categorias propostas pelo referido autor, como regras evolutivas e lineares.

Percebe-se também relativa aproximação entre Huberman (1992) e Shulman (2005) frente ao desenvolvimento da carreira, pois ambos consideram o início profissional hesitante, momento de maturação e significativa insegurança frente às escolhas. Mas, para os dois autores o tempo, em muitos casos, pode ser um ganho. Compreende-se que Shulman relativiza as noções de maturação, evolução, progresso, sobretudo ao afirmar que, muitas vezes, professores experientes podem atuar de modo vacilante e pouco favorável ao ensino, do mesmo modo que professores 'noviços'. Contudo, considerou-se que o tempo de profissão, ainda que recoberto de ressalvas, é um importante aspecto constituinte do profissional da docência, podendo-se inclusive, tanto para Shulman, como Huberman, indicar ações docentes similares.

Para Huberman, professores que tem entre um a cinco anos de profissão, genericamente,

Geografia Ensino \& Pesquisa, v. 17, n.1 p. 119-132, jan./abr. 2013

O conhecimento do conteúdo relevo: contribuições metodológicas embora mais próximos dos conhecimentos acadêmicos que os formaram, encontram-se ainda em um processo de tateamento da profissão, podendo inclusive, dela desistir. Os docentes entre seis e dez anos de magistério se consideram mais consolidados e imersos na profissão, estando assim, geralmente, numa fase de investimento profissional, mesmo que relativamente distanciados (cronologicamente) de sua formação inicial. Com base nesses pressupostos, assumiu-se que o tempo de profissão dos sujeitos dessa pesquisa seria entre 01 e 10 anos. 
Shulman (2001), sem demarcar expressamente os anos de vivência profissional, identifica diferenças entre o PCK dos jovens professores e o PCK dos professores mais experientes. Os últimos são vistos pelo autor como mais competente no desempenho de suas práticas letivas, pois teriam maior repertório de conhecimentos pedagógicos.

Desse modo, mesmo admitindo limites nas discussões sobre ciclo profissional (HUBERMAN, 1992) e as diferenças entre os contextos canadense, estadunidense e brasileiro, decidiu-se o tempo de profissão como um critério razoável para a seleção dos professores pesquisados, adotando-se duas das fases profissionais demarcadas pelo referido autor. As ideias de ambos - Shulman e Huberman -, sofrendo necessárias relativizações, foram parcialmente apropriadas para a escolha dos sujeitos. A relação tempo de profissão e repertório pedagógico, dito por Shulman (1986; 2001), foi olhada como possível elemento a ser considerado quando da interpretação das entrevistas dos professores. Estariam os professores 'expertos' mais seguros diante do conhecimento do conteúdo relevo?

Estabelecidos os parâmetros de seleção dos sujeitos, deparou-se com uma outra questão metodológica: onde e como encontrar os professores de Geografia a serem pesquisados?

A princípio, pensou-se em tornar os professores observados pelos alunos desta autora durante os Estágios Supervisionados. Entretanto, dois aspectos indicaram fragilidades nessa opção. Primeiramente, os estágios eram realizados, em sua maioria, em escolas públicas, principalmente em escolas das redes estaduais e municipais, pois raramente escolas privadas aceitam estagiários. Esta pesquisa aspirava contar com sujeitos trabalhadores em espaços privados e espaços públicos, de modo que características específicas a um ambiente não reduzissem os dados da pesquisa ao profissional de um tipo específico de rede de ensino. Avaliou-se que a escolha de professores atuantes apenas nas redes públicas, poderia levar à relativa homogeneidade entre os sujeitos de pesquisa e, assim, os conhecimentos identificados poderiam ser interpretados, 'mecanicamente', como específicos a um determinado grupo de docentes.

Como selecionar sujeitos de pesquisa, que se encontram dispersos em seus locais de trabaIho? Como identificar docentes que assegurassem trabalhar o conteúdo relevo e também atuassem no segundo segmento do Ensino Fundamental?

A resposta surgiu do inesperado. Ao ministrar um curso de formação docente junto ao Sindicato dos Professores local, comentou-se sobre o objeto que se estava investigando e sobre a delicadeza do ato de definição de uma amostra. Ao final do curso, 15 professores procuraram esta pesquisadora dizendo-se interessados em participar como sujeitos da pesquisa e deixando dados para o contato. Esta oferta espontânea, levou à decisão por abandonar a possibilidade de selecionar professores observados (via registro discente) durante os estágios.

Após 18 meses da finalização do curso, buscou-se contatar o grupo de professores que havia se voluntariado. Do grupo inicial, somente seis professores mostraram-se ainda disponíveis; quanto aos demais, quatro não foram localizados e cinco afirmaram a falta de tempo para a participação naquele momento.

Assim, procurou-se identificar se os seis professores restantes correspondiam aos critérios definidos para a seleção dos sujeitos. Neste conjunto, dois professores apresentavam mais de 18 anos de profissão e lecionavam para o ensino médio, não atendendo a dois dos requisitos iniciais. Os outros quatro docentes atendiam aos critérios necessários, mas todos tinham entre dois e seis anos de profissão, além de trabalharem somente na rede privada de ensino. Portanto, o grupo não poderia ser definido somente com estes voluntários.

Era essencial buscar outros sujeitos com tempo profissional entre seis e dez anos de carreira. Novamente, ao abordar a temática de pesquisa em um curso para professores da rede municipal, obteve-se novo grupo de voluntários, o que o possibilitou o fechamento do um grupo de nove professores, potencialmente, sujeitos da investigação.

A constituição de um grupo de voluntários foi avaliada positivamente, sobretudo considerando-se que cada entrevista durou, em média, 3 horas e se realizou em um espaço específico,

Geografia Ensino \& Pesquisa, v. 17, n.1 p. 119-132, jan./abr. 2013

Ascenção V. O. R.

ISSN 2236-4994 125 
reservado, previamente demarcado e fora do ambiente profissional do docente, exigindo assim um deslocamento. Todas essas exigências quando explicitadas ao conjunto de voluntários levou a redução do grupo que se alterou de nove para cinco professores - três docentes da rede privada, 01 da na rede pública municipal e um da rede pública estadual.

Para efeito de identificação dos sujeitos e de seus posicionamentos, optou-se por denominá-los através de letras do alfabeto. Essas letras não remetem ao nome dos professores, que foram apresentados e 'nomeados' aleatoriamente e não seguindo a ordem das entrevistas. Estas medidas visaram resguardar a identidade dos professores entrevistados.

$O$ sujeito de pesquisa A trabalha na rede privada de ensino, no município de Belo Horizonte e possui quatro anos de exercício profissional. Graduou-se somente em licenciatura na Universidade Federal de Minas Gerais. Atualmente, cursa o Mestrado em Geografia na mesma universidade.

$O$ professor B atua na rede municipal de ensino há quatro anos. Graduou-se em Geografia pela Universidade Federal de Minas Gerais, instituição pela qual obteve o título de mestre em Geografia.

$\mathrm{O}$ docente $\mathrm{C}$ possui habilitação como bacharel e licenciado em Geografia. Formou-se pelo Centro Universitário de Belo Horizonte, cursou especialização em Geoprocessamento. Contabiliza cinco anos de docência, atuando também como coordenador da área de Geografia em uma escola privada.

Graduado em licenciatura pela Universidade Federal de Minas Gerais e Mestre em Geografia na mesma instituição, o sujeito de pesquisa $D$ trabalha em uma escola privada, tendo 09 anos de vivência profissional. Finalmente, o professor E tem cargo efetivo na rede estadual de Minas Gerais. Formou-se pela Pontifícia Universidade Católica de Minas Gerais há oito anos, onde também desenvolveu seu mestrado. É também professor em uma instituição de Ensino Superior, trabalhando no curso de Engenharia Ambiental.

A definição dos sujeitos de investigação leva o pesquisador não apenas a uma fonte de dados. Mais do que isso essas pessoas tornam-se parceiros do trabalho, cuja disposição é essencial para o desenvolvimento do trabalho pretendido.

\section{O que conhecem os sujeitos do conhecimento?}

Definido o grupo de pesquisa partiu-se para a realização das entrevistas, cujos instrumentos buscaram articular-se às ideias de Shulman (2001) acerca do conhecimento da matéria ou do conteúdo. Apropriando-se, parcialmente, das metodologias empregadas pelo referido autor, optou-se pela realização de um conjunto de entrevistas: uma entrevista semi-estruturada e duas entrevistas projetivas, realizadas em sequência uma da outra.

A entrevista projetiva utiliza recursos visuais a fim de se obter os dados objetivados. Através de recursos visuais (imagens fotográficas, filmes, esculturas) o entrevistador busca, por meios indiretos, identificar os aspectos de interesse da pesquisa (DUARTE, 2002).

Como se afirmou, as três ações metodológicas não pretenderam, em nenhum momento, aferir os conhecimentos docentes e posteriormente distingui-los (os docentes), entre os sabem e os que sabem menos. Todos os instrumentos tiveram o objetivo comum de identificar conhecimentos relativos ao relevo, mobilizados pelos entrevistados diante de diferentes situações.

As questões apresentadas nas entrevistas foram construídas segundo a compreensão da

Geografia Ensino \& Pesquisa, v. 17, n.1 p. 119-132, jan./abr. 2013

O conhecimento do conteúdo relevo: contribuições metodológicas estrutura do conhecimento da matéria postulado por Grossman, Wilson e Shulman (2005). A decisão por tomar esse referencial teórico para estruturação dos meios de investigação apoia-se na compreensão de que, para os referidos autores, o conhecimento da matéria é uma referência epistemológica para o entendimento dos conhecimentos docentes.

Assim a pesquisa assumiu duas frentes investigativas: $\mathrm{i}$ - identificar os conhecimentos mobilizados pelos docentes ao lecionar o conteúdo relevo junto a seus alunos; ii - identificar os conhe- 
cimentos mobilizados pelos docentes frente a uma forma de relevo constituinte de seu cotidiano.

Em princípio, pode parecer ao leitor que somente a primeira frente atenderia aos objetivos e ao objeto da pesquisa. Entretanto, coerente aos referidos autores, a falta ou a precariedade dos conhecimentos da matéria por parte dos professores pode afetar os processos de ensino e aprendizagem. Portanto, é relevante identificar o que um professor sabe sobre um dado conteúdo. Esse é um dado qualitativo e avaliou-se que sua identificação poderia ocorrer a partir da interpretação de uma paisagem (SANTOS, 1988) pelo professor.

Considerou-se ainda que, a interpretação da espacialidade do elemento relevo demanda a articulação entre conceitos referentes aos processos, às formas e à dimensão escalar.

O Instrumento de Pesquisa I (entrevista semi-estruturada), apresentou aos entrevistados perguntas previamente organizadas, mas que, ao mesmo tempo, permitiam estabelecer uma conversação continuada, deixando que o sujeito pesquisado emitisse impressões e opiniões frente ao que se perguntava.

O que influencia a seleção dos conhecimentos sobre o relevo que você irá trabalhar com seus alunos?

Em sua prática pedagógica, que formas e processos do relevo você considera mais importante para trabalhar junto aos seus alunos?

Para você existe uma categoria da análise espacial que favoreça o trabalho com o conteúdo relevo junto a alunos do ensino fundamental?

Tais questões integraram o Instrumento de Pesquisa I e trouxeram indicativos sobre as escoIhas curriculares dos professores frente ao conhecimento do conteúdo, dado importantíssimo para a posterior interpretação do comportamento docente frente à matéria relevo.

Para além dos conhecimentos mobilizados junto aos alunos, procurou-se identificar os conhecimentos da matéria relevo mobilizados pelos docentes quanto da interpretação de uma paisagem.

Neste momento da investigação, desenvolveram-se instrumentos inspirados em recursos metodológicos utilizados pelo Repertório Grid.

O Repertório Grid consiste em uma metodologia que busca identificar as percepções dos sujeitos frente a um dado estímulo. Segundo Fernandes (2001), essa metodologia favorece ao pesquisador a observação dos referenciais utilizados por um indivíduo a fim de dar sentido a um determinado conjunto de acontecimentos, considerando-se a interação entre os elementos que o compõe.

Buscou-se identificar os conhecimentos da matéria que orientam o professor quando da análise de um relevo. Entretanto, as condições para a entrevista não favoreciam saídas a campo com cada um dos sujeitos de pesquisa. Desse modo, sendo impossível identificar tais conhecimentos a partir de uma realidade imediata, considerou-se relevante apresentar uma realidade percebida.

A concepção de realidade percebida foi tomando-se com base nos referenciais teóricos atinentes à cognição espacial, elaborados por Piaget \& Inhelder (1993), compreende-se como percebida dimensões espaciais visiveis através de imagens fotográficas ou recompostas, pela fala, através do recurso à memória. No presente trabalho utilizou-se a fotografia a fim de evocar os conhecimentos da matéria dos docentes. Entende-se que através desse recurso de visualização, seja possível favorecer aos sujeitos cognitivos a percepção de diferentes elementos constituintes de uma dada espacialidade. Tal escolha corrobora com a compreensão de que a análise espacial exige a articulação entre componentes diversos, os quais, em articulação, conformam espacialidades. Assim, avaliou-se que a fotografia poderia permitir aos sujeitos a interpretação espacial do elemento relevo.

Piaget \& Inhelder desenvolveram seus estudos junto à criança, entretanto, toma-se como pertinente a ampliação das discussões com base nesses autores, para se tratar da apreensão do espaço geográfico junto aos sujeitos cognitivos, independente de sua idade.

Assim, apresentou-se aos sujeitos de pesquisa, o Instrumento de Pesquisa II, composto pela imagem de uma vertente e um conjunto de palavras ou expressões referentes aos conhecimentos

Geografia Ensino \& Pesquisa, v. 17, n.1 p. 119-132, jan./abr. 2013

\section{Ascenção V. O. R.}

ISSN 2236-4994 
sobre a matéria relevo, tais como tipos de formas, processos e escala de abrangência do fenômeno visível através da imagem (Figura I). Excetuando-se as expressões Tempo Histórico, Tempo Geológico, Escala Local, Escala Global, todas as demais expressões foram repetidas quatro vezes no conjunto, de modo a oferecer opções de análise para o entrevistado.

A partir da conjugação desses elementos (imagem e palavras), realizou-se a observação e identificação de conhecimentos mobilizados pelos professores frente a leitura de uma forma recorrente no cotidiano desses sujeitos: a vertente, Figura 1.

Figura I- Instrumento de Entrevista

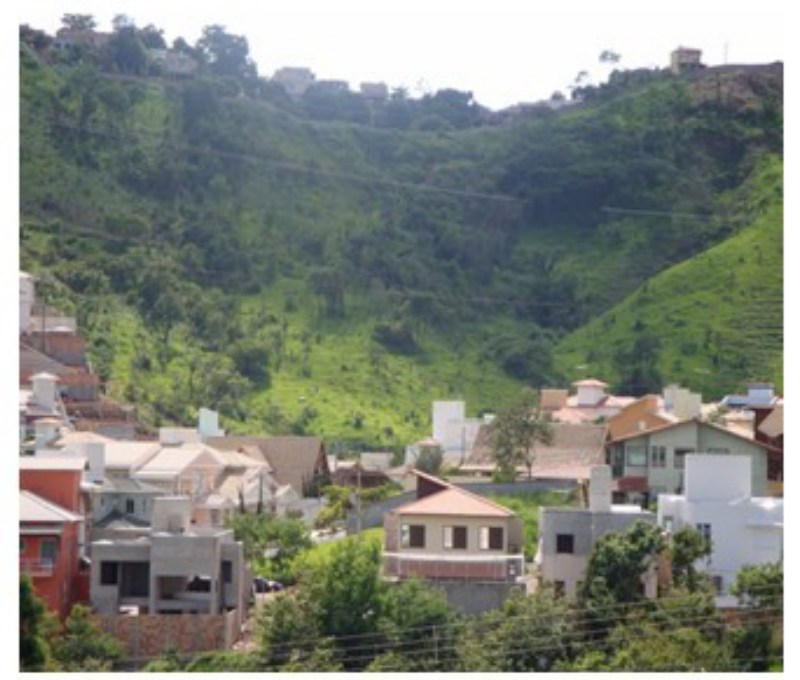

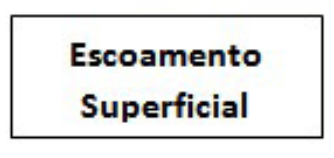
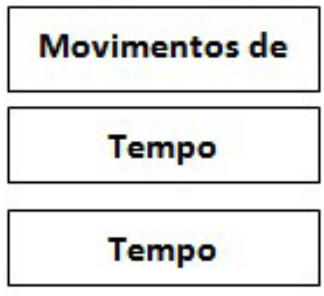

Ravina
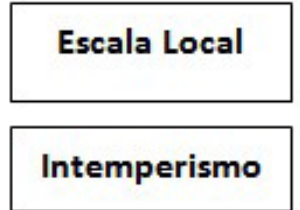

Erosão

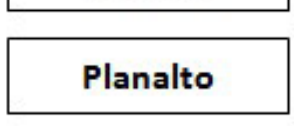

Depressão

\section{Escala Global}

Infiltração
Geografia Ensino \& Pesquisa, v. 17, n.1 p. 119-132, jan./abr. 2013

O conhecimento do conteúdo relevo: contribuições metodológicas

A partir da conjugação desses elementos (imagem e palavras), realizou-se a observação e identificação de conhecimentos mobilizados pelos professores frente à leitura de uma forma recorrente no cotidiano desses sujeitos: a vertente.

O Instrumento de Pesquisa III teve por meta trabalhar com a abstração reflexiva do professor. A noção de abstração reflexiva dialoga com a noção de abstração empírica, ambas presentes na obra de Piaget $(1967 ; 1976)$. Com base nesse autor, afirma-se que abstrair é uma capacidade humana e todos abstraem. Entretanto, para Piaget (1976), existem dois modos de abstração, correlativos entre si.

O primeiro, denominado abstração empírica, refere-se à capacidade do sujeito cognitivo refletir sobre os objetos estando em contato direto (ativo) com eles ou através de contato perceptivo. $O$ segundo instrumento de entrevista apoiou-se nessa capacidade abstrativa.

A elaboração do último e terceiro instrumento teve por base a noção de abstração reflexiva; os entrevistados foram estimulados a refletir sobre o relevo e suas dinâmicas a partir das mesmas palavras utilizadas pelo segundo instrumento de entrevista. Nessa terceira fase, a partir das palavras disponibilizadas, solicitou-se aos entrevistados que esses construíssem um esquema de racio- 
cínio conceitual relativo à organização do relevo. Para tanto, os entrevistados deveriam estabelecer associação entre as palavras, de modo a explicar formas e processos constituintes da paisagem fotográfica utilizada pelo Instrumento de Pesquisa II.

Os três instrumentos usados na coleta de dados contribuíram para o aclaramento de aspectos referentes ao conhecimento do conteúdo pelo docente.

De modo geral, destaca-se que os professores acabam por embaraçar sua percepção quando, ao observar o relevo na escala local (vertente), acaba por buscar explicação para processos e formas somente na escala geológica, ou, como afirma Suertegaray (2002), nos tempos longos. Os professores parecem condicionados a fornecer explicações segundo uma sequência cronológica cuja referência é o Tempo Geológico e não o Tempo Histórico.

$\mathrm{Na}$ atualidade, coloca-se à Geografia Escolar a função de construir, junto aos alunos, um raciocínio espacial a partir de conceitos e competências da ciência de origem dessa disciplina. Esse raciocínio, ainda que demande o trânsito entre escalas, deve, sobretudo, contribuir para que o educando interprete seu espaço de vivência e se assuma produtor do espaço.

A situação espacial apresentada pela fotografia permitia a interpretação da espacialidade do relevo, com base no Tempo Histórico e em argumentos de base na morfodinâmica (visíveis no tempo curto). Tomado nessa perspectiva, o relevo pode ser assumido pelos alunos como elemento sobre o qual se age, mas que também reage a ação humana. A pequena escala e o Tempo Geológico geram abordagens do relevo que independem da ação humana. Contudo, os professores realizam interpretações do local através de conceitos e processos invisíveis no tempo histórico, processos de origem morfogenêtica.

Constrói-se assim uma questão de ordem epistêmica, a partir da qual se entende que as bases explicativas que referendam a leitura do professor, pouco contribuem para a interpretação do fenômeno na escala do vivido, do cotidiano imediato. Tal abordagem do conhecimento do conteúdo pode inibir, ao aluno, raciocínios que associem o conteúdo escolar a seu espaço vivido, indo assim de encontro com as propostas recentes postas ao ensino de Geografia.

\section{Considerações}

Argumentou-se que para toda pesquisa as reflexões metodológicas configuram um aspecto central. Entretanto, não raras vezes, encontram-se trabalhos que reduzem a metodologia a procedimentos e instrumentos que, aparentemente, não passaram por um crivo teórico ou, até mesmo, desfavorecem a interpretação daquilo que se pretende investigar.

Ainda que não se tenha a pretensão de considerar as exposições anteriores como uma saída inequívoca, buscou-se aqui evidenciar que exercícios teóricos são fundamentais para a construção do percurso metodológico de uma pesquisa.

Intencionou-se demarcar que a complexidade do objeto de estudo acaba por produzir a necessidade de fontes de pesquisa, como também solicitar instrumentos interpretativos vários, de origens múltiplas, mas, coerentemente arregimentados.

Ressalta-se ainda que, neste trabalho se pretendeu um distanciamento das abordagens prescritivas, aspirando somente apontar possibilidades para as investigações acerca dos conhecimentos dos docentes geógrafos.

Avalia-se que as opções metodológicas aqui expostas foram essenciais para o mapeamento inicial dos conhecimentos dos docentes geógrafos frente ao conteúdo relevo. Os referenciais teóricos que subsidiaram a pesquisa e embasaram os encaminhamentos metodológicos foram basilares para a identificação qualitativa de modus de operação conceituais pelos professores.

Em geral, reconhece-se a importância das ações metodológicas em atividades de pesquisa; arrisca-se a afirmar que a metodologia é o eixo vertebral de uma pesquisa. Pois, através das reflexões metodológicas pode-se visualizar a necessidade de reorganização das bases teóricas, de

Geografia Ensino \& Pesquisa, v. 17, n.1 p. 119-132, jan./abr. 2013

Ascenção V. O. R. 
lapidação dos objetivos, de redefinição de instrumentos e ações de pesquisa. Por isso, destaca-se a necessidade de que as discussões metodológicas superem a enumeração de ações, descoladas das orientações teóricas que as respaldaram. Há muito combate-se a ideia de uma metodologia limitada a procedimentos, contudo, ainda na atualidade, são muitos os trabalhos no campo da Geografia que simplificam a noção de metodologia e, até mesmo, que omitem a esfera metodológica do corpo do seu texto. Acredita-se que essas atitudes corroborem, em muitos casos, para o esvaziamento das reflexões pretendidas pelas pesquisas.

\section{Referências}

ALLAIN, L. e outros. Implicações das Novas Tecnologias na Prática Pedagógica de Professores de Ciências, Geografia e História das séries iniciais: um recorte pedagógico e comunicacional. Belo Horizonte, Universidade FUMEC, 2005.

ANDRÉ, MARLY. A Jovem Pesquisa Educacional Brasileira. Revista Diálogo Educacional, vol. 6, núm. 19, Set./Dez. Pontifícia Universidade Católica do Paraná, 2006. Curitiba. pg. 11-24. Disponível em: http://redalyc.uaemex.mx/redalyc/pdf/1891/189116275002.pdf. [Acesso em: 24 de outubro de 2012]

ANJOS, Daniela D. Reconsiderações sobre o "início" na profissão docente. $\mathbf{2 8}^{\mathrm{a}}$ REUNIÃO DA ANPED, 2008. Caxambu, Minas Gerais. Disponível em: <http//www.anped.org.br/reuninoes/28/ textos/gt20> [Acesso em: 15 de maio de 2009].

BARDIN, Laurence. Análise de Conteúdo. Lisboa: Edições 70, 1971.226 p.

BERNSTEIN, Basil. Pedagogia, Control Simbólico e Identidad. Madrid: Ediciones Morata, 1986.

BERNSTEIN, Basil. A Pedagogização do conhecimento: estudos sobre recontextualização. In: Cadernos de Pesquisa, n. 120, p. 75-110, novembro/ 2003. Instituto de Educação da Universidade de Londres. Tradução: Maria de Lourdes Soares e Vera Luiza Visockis Macedo. Disponível em: <http://www.scielo.br>. [Acesso em: 20 dez. 2008.]

BHABA, Homi. O local da Cultura. Belo Horizonte: Editora UFMG, 1998. s/p

BORGES , CECÍLIA. Saberes docentes: diferentes tipologias e classificações de um campo de pesquisa. Educ. Soc., Campinas, v. 22, n. 74, 2001.

BRASIL. Secretaria de Educação Fundamental. Parâmetros Curriculares Nacionais para Geografia $3^{\circ}$ e $4^{\circ}$ ciclos (5a a $8^{a}$ séries). Brasília: MEC, 1998.156p.

BRUYNE, Paul et al. Dinâmica da pesquisa em ciências sociais: os polos da prática metodológica. Rio de Janeiro: Francisco Alves, 1977. DEL GAUDIO, Rogata S. Concepções de Nação e Estado Nacional dos Docentes de Geografia - Belo Horizonte no final do segundo milênio. 2006. 270f. Tese (Doutorado em Educação) - Faculdade de Educação, Universidade Federal de Minas Gerais, Bel Horizonte, 2006.

Geografia Ensino \& Pesquisa, v. 17, n.1 p. 119-132, jan./abr. 2013

O conhecimento do conteúdo relevo: contribuições metodológicas
Disponível em: <http://servicos.capes.gov.br/capesdw/> [Acesso em: 20 ago. 2008].

DUARTE, Rosália. Pesquisa qualitativa: reflexões sobre o trabalho de campo. Cadernos de Pesquisa, São Paulo, n. 115, mar. 2002.

FARIA, Manoel et ali O papel epistemológico da teoria e sua importância para o avanço da pesquisa 
em Contabilidade. In CONGRESSO USP DE CONTROLADORIA E CONTABILIDADE. São Paulo: FEA/USP, 2010. 1 CD-ROM.

FERNANDES, E. M. A grelha de Repertório. In: FERNANDES, E. M. et al. Métodos e técnicas de avaliação: contributos para a prática e investigação psicológicas. Braga: Universidade do Minho. Centro de Estudos em Educação e Psicologia, 2001. p. 77-107.

GARCÍA CANCLINI, Néstor. Noticias recientes sobre la hibridación. Revista Transcultural de Música,v.7. 2003. Disponível em http://www.sibetrans.com/trans/trans7/canclini.htm. [ Acesso em 10 de abr.2011].

GROSSMAN, Pamela; WILSON, Suzzane M.; SHULMAN, Lee S. Profesores de sustancia: el conocimiento de la materia para la enseñanza. Revista de currículum y formación del profesorado, v. 9, n. 2, 2005. Universidade de Granada. Disponível em: <http://www.ugr.es/ recfpro/ presentacion.html>. [Acesso em: 01 mai. 2009].

HUBERMAN, Michäel. O ciclo de vida profissional dos professores. In: NÓVOA, António (org). Vida de professores. Porto Editora. Portugal. 1992.

PEREZ, Daniel Gil e outros. Para uma imagem não deformada do trabalho científico. Revista Ciência \& Educação, v.7, 2001. Disponível em: http://www.scielo.br/pdf/ciedu/v7n2/01.pdf [ Acesso em 22/06/2012].

PIAGET, J. \& INHELDER, B. A representação do espaço na criança. Tradução Bernadina Machado de Albuquerque. Porto Alegre: Artes Médicas, 1993.

PIAGET, Jean. A equilibração das estruturas cognitivas - problema central do desenvolvimento. .Rio de Janeiro: Zahar Editores, 1976.

ROQUE ASCENÇÃO, V. O. A formação disciplinar e os processos pedagógicos em mudança: os professores de Geografia na Escola Plural de Belo Horizonte. 232p. Dissertação (Mestrado em Educação). Faculdade de Educação, Universidade Federal de Minas Gerais, 2003.

ROQUE ASCENÇÃO, V. O. Do professor Ideal ao Professor real - o que disseram os documentos da Escola Plural. In: ENCONTRO DE PESQUISA EM EDUCAÇÃO DA REGIÃO SUDESTE - POLITIICA CONHECIMENTO E CIDADANIA, $6^{a}$ Reunião Anual da Associação Nacional de Pós-graduação em Educação (ANPEd), Rio de Janeiro, Rio de Janeiro 2004. Disponível em CD-ROM.

SANTOS, Milton. Metaformoses do Espaço Habitado. São Paulo: Hucitec, 1988. 28p.

SHULMAN, L. S. Those who understand: knowledge growth in teaching. Educational Researcher, Washington, v.15, n. 2, p. 4-14, 1986. CONOCIMIENTO Y ENSEÑANZA. Revista Estudios Públicos, vol.83, Chile 2001. CONOCIMIENTO Y ENSEÑANZA: Fundamentos de la nueva reforma. Revista de currículum y formación del profesorado, Vol.9, 2005. Disponível em: <http://www.ugr. es/local/recfpro/Rev92ART1.pdf>. [Acesso em: 20 de ago. 2008].

Geografia Ensino \& Pesquisa, v. 17, n.1 p. 119-132, jan./abr. 2013

SUERTEGARAY, Dirce M. A. Tempos Longos... Tempos Curtos... na Análise da Natureza. Geografares, Vitória, $n^{0} 3$, jun.2002. p. 159-163. 


\section{Correspondência:}

Valeria de Oliveira Roque Ascenção- Rua dos Corretores, n.149. Bairro Alípio de Melo, Belo Horizonte. Cep 30840-060.

E-mail:valeriaroque@gmail.com

Recebido em 23 de janeiro de 2012.

Revisado pelo autor em 21 de dezembro de 2012.

Aceito para publicação em 04 de janeiro de 2013. metodológicas 